\title{
FORMAÇÃO DOCENTE E TRABALHO EDUCATIVO NA EDUCAÇÃO INFANTIL: ALGUMAS REFLEXÕES ${ }^{1}$
}

\author{
TEACHER EDUCATION AND EDUCATIONAL WORK IN EARLY CHILDHOOD \\ EDUCATION: SOME REFLECTIONS
}

\author{
Ilaine Inês Both \\ Doutora em Educação \\ Universidade Federal do Amazonas - UFAM \\ Manaus, Amazonas - Brasil \\ laineines@yahoo.com.br \\ Michelle de Freitas Bissoli \\ Doutora em Educação \\ Universidade Federal do Amazonas - UFAM \\ Manaus, Amazonas - Brasil \\ mibissoli@yahoo.com.br
}

\begin{abstract}
Resumo: A formação docente superficial e pragmática colabora para o esvaziamento do trabalho educativo e do processo de humanização. Esses fenômenos se coadunam com as limitadas condições de vida e de educação da ampla maioria das mulheres e dos homens do nosso país, fruto da estrutura social vigente, organizada na lógica do capital. Essa afirmação resulta da pesquisa de doutorado, vinculada ao Programa de Pós-Graduação em Educação (PPGE), da Universidade Federal do Amazonas (UFAM), que analisou, sob a luz da Teoria Histórico-Cultural e da Pedagogia Histórico-Crítica, elementos do trabalho educativo desenvolvido em 2014, com crianças da pré-escola de uma escola pública municipal de Manaus, Amazonas. A observação participativa em uma turma frequentada por vinte crianças de 4 e 5 anos de idade e o Grupo Focal com três professoras da pré-escola foram os instrumentos principais da pesquisa de campo. O estudo demonstra que o trabalho educativo, categoria central dessa pesquisa, foi predominantemente caracterizado pelo pragmatismo e espontaneísmo, o que contribui para a manutenção do acentuado estado de desumanização de professores e crianças. A superação dessa situação passa pela socialização do conhecimento em sua forma mais elaborada, função precípua da escola. Para tanto, apontamos a unidade dialética entre a teoria e a prática na formação docente como uma das possibilidades para a necessária e desafiadora busca do aprimoramento do trabalho educativo na Educação Infantil.
\end{abstract}

Palavras-chave: educação infantil; formação docente; trabalho educativo.

\begin{abstract}
The superficial and pragmatic teacher education contributes to the emptying of educational work and the process of humanization. These phenomena are consistent with the limited living conditions and education of the vast majority of women and men in our country, as a result of the current social structure, organized in the logic of capital. This statement results from a PhD research, linked to the Postgraduate Program in Education (PPGE) of the Federal University of Amazonas (UFAM), which analyzed, under the light of Historical-Cultural Theory and Historical-Critical Pedagogy, elements of the educational work developed in 2014, with pre-school children from a municipal public school in Manaus, Amazonas. Participatory observation in a class attended by twenty children at the age of 4 and 5 years and the Focus Group with three pre-school teachers were the main instruments of field research. The study shows that the educational work, the central category of this research, was predominantly characterized by pragmatism and spontaneity, which contributes to the maintenance of the marked state of dehumanization of teachers and children. Overcoming this situation involves the socialization of knowledge in its most elaborate form, the primary function of the school. To this end, we highlight the dialectical unity between theory and practice in teacher education as one of the possibilities for the necessary and challenging pursuit of the improvement of the educational work in Early Childhood Education.
\end{abstract}

Keywords: child education; teacher training; educational work.

Para citar - (ABNT NBR 6023:2018)

BOTH, Ilaine Inês; BISSOLI, Michelle de Freitas. Formação docente e trabalho educativo na educação infantil: algumas reflexões. Eccos - Revista Científica, São Paulo, n. 57, p. 1-18, e13538, abr./jun. 2021. Disponível em:

https://doi.org/10.5585/eccos.n57.13538. ${ }^{1}$ Este artigo contou com o apoio financeiro da Fundação de Amparo à Pesquisa do Estado do Amazonas (FAPEAM), da Universidade Federal do Amazonas
(UFAM) e da Coordenação de Aperfeiçoamento de Pessoal de Nível Superior (CAPES) 


\section{Introdução}

Este texto é fruto da tese de Doutorado² intitulada "Esvaziamento do trabalho educativo na pré-escola, suas causas e implicações na formação das crianças: investigação em uma unidade escolar pública municipal em Manaus", vinculada à Linha de Pesquisa "Formação e Práxis do(a) Educador(a) frente aos Desafios Amazônicos” do Programa de Pós-Graduação em Educação (PPGE), da Universidade Federal do Amazonas (UFAM).

No estudo, investigamos o trabalho educativo desenvolvido, em 2014, na pré-escola, em uma unidade escolar pública municipal de Manaus, após a aprovação do Comitê de Ética em Pesquisa (CEP/UFAM) ${ }^{3}$. Foram sujeitos diretos da pesquisa de campo três professoras que atuaram com suas respectivas turmas da pré-escola e vinte crianças de uma dessas turmas. Por intermédio da observação participativa (GANDINI; GOLDHABER; BARROS, 2014), em uma turma de crianças da pré-escola, e do Grupo Focal (ANDRÉ, 2004; GATTI, 2005; MINAYO, 2010) com professoras da pré-escola da mesma unidade escolar, foi possível identificar elementos característicos do esvaziamento do trabalho educativo, fenômeno que integra o universo da organização social capitalista, atualmente hegemônica no Brasil e no mundo.

Considerando os resultados de nossa pesquisa (BOTH, 2016), optamos por enfocar a formação docente na reflexão que aqui nos propomos a realizar. Inicialmente, buscaremos discutir algumas relações entre a formação docente empobrecida, o esvaziamento do trabalho educativo e a sociedade capitalista. Em seguida, apontaremos como a formação continuada pode constituir uma das possibilidades para o enriquecimento da atuação docente das professoras e dos professores da Educação Infantil.

\section{Formação docente empobrecida: para quem, para quê?}

A pesquisa que realizamos (BOTH, 2016) nos permitiu compreender que há uma íntima relação entre a formação docente empobrecida, o esvaziamento do trabalho educativo e o processo de desumanização que atinge a ampla maioria da população do nosso país. Em outros termos, o esvaziamento do trabalho educativo, revelado pelas professoras que participaram de nossa pesquisa, não é um fenômeno isolado. Está, pelo contrário, implícito na estrutura social vigente, organizada sob a lógica do capital.

\footnotetext{
2 Apoio: Fundação de Amparo à Pesquisa do Estado do Amazonas - FAPEAM 
A sociedade organizada sob a lógica do capital promove a concentração dos produtos materiais (objetos tangíveis) e simbólicos (ideias, por exemplo) do trabalho - atividade especificamente humana - nas mãos de um pequeno grupo privilegiado, promovendo desigualdade social. Nesse sentido, o sistema capitalista, conduzido pela classe dominante ${ }^{4}$, não visa à socialização das riquezas materiais e simbólicas para o conjunto da população. Ao contrário, esta classe social busca utilizar todos os meios para intensificar o domínio que exerce sobre a classe trabalhadora ${ }^{5}$ e sobre a riqueza existente no mundo.

O fosso no acesso à riqueza material e simbólica existente entre a classe dominante e a classe trabalhadora atinge níveis alarmantes. Dados divulgados pela Organização Não Governamental (ONG) Oxfam indicam que, do total de riqueza produzida no mundo, em 2017, $82 \%$ ficou com $1 \%$ dos mais ricos do planeta (CORDEIRO, 2018). Indicadores da mesma ONG, referentes a 2018, apontam que o patrimônio das 26 pessoas mais ricas do mundo é equivalente ao de 3,8 bilhões mais pobres, que representam $50 \%$ da humanidade (MACIEL, 2019). Com relação ao nosso país, informações da Oxfam, publicadas em 2018, revelam que 5 bilionários brasileiros detêm patrimônio equivalente à renda de $50 \%$ da população mais pobre do Brasil (GOMES, 2018).

Enfatizamos que o debate sobre a formação docente deve considerar esse contexto. Sob nosso ponto de vista, a classe dominante engendra e lança expedientes também na formação dos professores e professoras, peças-chave na conformação da estrutura social vigente. A eles, em geral, é possibilitado o acesso mínimo aos conhecimentos, apenas o suficiente para atender aos interesses do capital.

Em se tratando, especificamente, da formação de professores da Educação Infantil etapa educacional que foi foco da nossa investigação -, algumas tendências formativas se instalaram no Brasil, a partir da década de 1990, e estão se fortalecendo, o que inclui, de acordo com Raupp (2008, p. 113-4):

\footnotetext{
${ }^{4}$ Utilizamos o termo classe dominante para nos referir à classe social que, na sociedade vigente, é formada por grandes capitalistas que detêm a posse de quase "todos os meios de existência e das matérias-primas e dos instrumentos (máquinas, fábricas) necessários para a produção dos meios de existência" (ENGELS, $1982, \mathrm{~s} / \mathrm{p}$ ). Na sociedade vigente, também fazem parte aqueles que, por exemplo, vivem da especulação financeira e os "gestores e altos funcionários do capital" (ANTUNES, 2010, p. 201).

${ }^{5}$ A expressão classe trabalhadora a que nos referimos é similar com o sentido dos termos classe-que-vive-do-próprio-trabalho empregado por Leher (2012) e classeque-vive-do-trabalho utilizado por Antunes (2009; 2010). Conforme Antunes (2010, p. 200-1, grifos do autor), essa classe social compreende: "1) todos aqueles que vendem sua força de trabalho, incluindo tanto o trabalho produtivo quanto o improdutivo; 2 ) inclui os assalariados do setor de serviço e também o proletariado rural; 3) inclui proletariado precarizado, sem direitos, e também os trabalhadores desempregados, que compreendem o exército industrial de reserva e 4) exclui, naturalmente, os gestores e altos funcionários do capital, que recebem rendimentos elevados ou vivem de juros."
} 
[...] a influência dos organismos multilaterais na política educacional a qual define as diretrizes e programas para a formação das professoras da Educação Infantil; [...] 'descentralização' da formação das professoras de Educação Infantil com a incumbência da formação continuada aos municípios, sob orientações, em diretrizes/programas, do Ministério da Educação, pautadas na epistemologia da prática; [...] aligeiramento da formação inicial sobretudo com a ampliação do número de formação inicial integral à distância; [...].

Para nós, as questões que a autora levanta permitem inferir que a formação docente, em nosso país, é fortemente direcionada para o desenvolvimento das capacidades mínimas necessárias à integração ao sistema social vigente. Para ensinar a ler, escrever e contar, a formação de professores e professoras como intelectuais da Educação se torna mera retórica. Nesse sentido, organismos internacionais, como o Banco Mundial, a Organização das Nações Unidas para a Educação (UNESCO) e o Fundo das Nações Unidas para a Infância (UNICEF), buscam intervir na formação docente, com o intuito de adequar as políticas educacionais às políticas do sistema capitalista (RAUP, 2008).

Os professores e professoras, com pouco repertório de conhecimentos, dificilmente terão elementos que lhes permitam compreender os interesses que permeiam as ações desses organismos no campo educacional que, enfatizamos, estão comprometidos com a perpetuação da lógica capitalista. Consideramos que a formação docente, interposta pelo pragmatismo e voltada para o desenvolvimento das competências, por exemplo, se insere nesse contexto.

Derisso (2010, p. 57) afirma que a pedagogia das competências reelaborou e incorporou, na última década do século XX, o construtivismo. Dessa forma, “[...] a pedagogia construtivista nos aparece mais pragmática, uma vez que coloca abertamente a preocupação com a adaptação do estudante à nova realidade do capitalismo globalizado."

A ideia da vinculação da formação educacional a determinados interesses da sociedade é reiterada por Silva (2014). O estudioso afirma que a formação dos professores é, em geral, estabelecida em conformidade com o tipo de profissional requerido por uma determinada sociedade visando a sua autopreservação.

Isso produz paradoxos: enquanto as exigências profissionais a professores e professoras se ampliam e se diversificam cada vez mais - à escola são atribuídas tarefas e obrigações que se sobrepõem à sua real função social -, suas condições e tempo de formação têm diminuído por conta da expansão desenfreada de cursos aligeirados e a distância, muitas vezes, sem condições estruturais nem quadro de formadores qualificado. Consideramos que essa situação se deve, em parte, à imposição de metas quantitativas, estabelecidas por organismos 
internacionais, para que os governos municipais, estaduais e federal tenham acesso a recursos financeiros.

Gatti (2010) ressalta a necessidade de atenção com relação ao público que frequenta cursos de graduação, sobretudo a distância. A autora assegura que a formação docente mais aligeirada e a distância são destinadas, em geral, a estudantes que já tiveram desfavoráveis condições educacionais nas etapas anteriores.

Raupp (2008) contribui no debate sobre o aligeiramento e a desintelectualização na formação docente. A estudiosa argumenta que essa formação está envolta por um movimento que prestigia o pragmatismo em detrimento da reflexão teórica, o que se contrapõe à práxis. Sabemos que a práxis é imprescindível na busca da educação escolar com qualidade socialmente referendada.

Shiroma (2003, p. 76-7) afirma que a desintelectualização em curso na formação de professores dificulta que eles compreendam que o conjunto de soluções dos problemas do processo educativo “[...] não advém apenas da reflexão sobre sua prática, especialmente quando enclausurada no espaço da sala de aula ou limitada pelos muros escolares. Isto é, a reflexão sobre a prática é necessária, porém insuficiente.” E tal insuficiência se justifica porque são múltiplas as relações e determinações que influem no fenômeno educacional e sua compreensão efetiva passa pela mediação de abstrações e exige o exercício do pensamento teórico (BISSOLI; BOTH, 2016).

Essa ideia de Shiroma está em consonância com a concepção de Moraes (2001; 2009), ao argumentar sobre o retrocesso, em curso no campo educacional de nosso país, de discussões e reflexões de caráter teórico. Sob nosso ponto de vista, isso não significa menosprezar os conhecimentos procedimentais na formação docente. As técnicas, entretanto, não são suficientes para o trabalho intelectual que é requerido dos professores e professoras, que são, sobretudo, profissionais que interferem no desenvolvimento das capacidades especificamente humanas e da personalidade das novas gerações.

$\mathrm{O}$ fato é que tanto o professor e a professora que realizaram/realizam curso presencial quanto aqueles que o fizeram/fazem na modalidade a distância têm, diante de si, exigências profissionais cada vez maiores. Nesse sentido, defendemos que todos precisam de uma formação que lhes possibilite o domínio do conteúdo e da forma para efetivar o trabalho educativo na perspectiva de elevar as capacidades humanas das crianças. 
Isso pressupõe a não centralidade da teoria ou da prática e, no Ensino Superior, a não sobrevalorização da pesquisa em detrimento da docência. Assim, consideramos importante atentar para a afirmação de Fernandes (2014, p. 115, grifos do autor):

[...] historicamente, a pesquisa nas universidades públicas foi mais valorizada do que a docência e, em tempos de lattescracia, isso se acentuou. [...] $\mathrm{Na}$ carreira universitária, onde atividades realizadas se transformam em pontos sintetizados em planilhas, a pesquisa, muitas vezes sem nenhum tipo de impacto social, é superdimensionada em relação à docência e às ações que desta decorrem. Não há dúvidas em afirmar que muitos docentes universitários que lutam pela garantia de cursos de formação de professores com qualidade e atuam com competência e compromisso nas licenciaturas, o fazem por questões ideológicas, por defenderem os princípios da educação como ideal republicano.

A argumentação do autor é similar à concepção de Silva (2014, p. 89), para quem “[...] há professores universitários atuantes nas licenciaturas que consideram a formação pedagógica do futuro professor como algo secundário”. Em nossa perspectiva, a sobrevalorização da pesquisa em detrimento da docência e vice-versa fomentam um hiato entre conteúdo e forma, o que gera formação unilateral dos futuros professores.

Assim, enfatizamos que a perspectiva de formação docente inicial e continuada que defendemos tem em vista a construção do elo entre o conteúdo e a forma, da unidade dialética entre a teoria e a prática, para a efetivação da práxis. Desse modo, os métodos e as técnicas de ensino se articulam com os fundamentos da educação visando à formação humanizadora (MILLER; BARBOSA; MENDONÇA, 2014), à formação omnilateral (BISSOLI, 2005).

No que diz respeito à formação inicial, vislumbramos possibilidades que acreditamos serem capazes de contribuir significativamente para o enriquecimento formativo dos graduandos, o que inclui o conhecimento sobre as singularidades das crianças e suas infâncias e as especificidades da Educação Infantil. Nesse sentido, defendemos a inserção dos estudantes em unidades escolares de Educação Infantil (creches e pré-escolas) e dos anos iniciais do Ensino Fundamental ao longo da sua formação acadêmica, a partir dos períodos iniciais do curso de Pedagogia. Essa inserção pode-se efetivar por intermédio de pesquisa de campo orientada pelos professores formadores e atividades de extensão e elaboração, desenvolvimento e socialização de Pesquisas de Iniciação Científica, por exemplo.

Com relação à formação continuada, discussão que privilegiamos neste texto, teceremos algumas considerações a seguir, incluindo, em nossas reflexões, aspectos da realidade observados na pesquisa de campo (BOTH, 2016). 


\section{Formação continuada: em busca do enriquecimento do trabalho educativo}

Com base em nossa investigação, apontamos a formação continuada como elemento essencial para o exercício da práxis, condição necessária para superar a lógica desumanizadora do capital. A busca consiste, portanto, em estreitar o elo entre a teoria e a prática, visando ao enriquecimento do trabalho docente, o que se insere na luta contra as atuais relações sociais de dominação.

No que tange à Educação Infantil, ressaltamos que a qualidade do atendimento das crianças passa pela sólida formação docente inicial, que deverá ser constantemente aprimorada no exercício concreto da profissão. Sabemos que o reconhecimento dos profissionais da Educação Infantil como professores ocorreu somente com a Lei de Diretrizes e Bases da Educação Nacional (LDBEN) vigente (BRASIL, 1996), o que, sem dúvida, foi uma conquista importante para esta que é a primeira etapa da Educação Básica brasileira.

Todavia, a previsão legal não significa a materialização da lei. Mesmo passados mais de vinte anos da aprovação da citada LDBEN, ainda se tem notícia de professores atuando na Educação Infantil, em nosso país, sem a devida formação. Entendemos que isso se deve, em parte, à concepção segundo a qual, para atuar na Educação Infantil, não é necessária formação docente especializada e consistente. Isso, sem dúvida, demonstra conhecimento rarefeito sobre o processo de formação humana que se inicia nas primeiras semanas de vida do bebê.

Soma-se a isso o desprestígio do professor e da professora de Educação Infantil presente no campo educacional brasileiro, inclusive, por parte de professores que atuam em outras etapas e níveis da educação escolar e que menosprezam os colegas que atuam com crianças de 0 a 5 anos de idade, considerando-os menos importantes. Assim, o cargo de professor e de professora da Educação Infantil carrega as marcas da trajetória histórica percorrida por essa etapa da Educação Básica e, por conseguinte, é caracterizado por equívocos conceituais no que se refere às concepções de criança, infância, papel do professor e da escola no processo de formação dos seres humanos nos primeiros anos de vida.

Com base, principalmente, na Teoria Histórico-Cultural e na Pedagogia HistóricoCrítica, defendemos a formação enriquecida dos professores e professoras que atuam na Educação Infantil, com o auxílio de distintas áreas do conhecimento, como: Psicologia, Filosofia, História, Sociologia, Artes, Didática, Educação Física. Assim, ressaltamos a necessidade de elevada apropriação de conhecimentos teóricos (conteúdos) e metodológicos (formas) pelo professor e pela professora para impelir o desenvolvimento humano deles próprios e das crianças. 
Concordamos com Mello (2007, p. 15), quando evoca a importância da formação docente sólida. A autora assegura que "muito do que temos feito com a educação das nossas crianças carece de uma base científica e, frente aos novos conhecimentos que temos hoje, podemos perceber alguns equívocos nas práticas que muitos de nós realizamos na educação das crianças."

Entendemos que a afirmação da autora diz respeito tanto aos professores que atuam na formação docente, quanto aos professores que atuam diretamente com as crianças nas escolas. No caso das professoras da pré-escola da escola em que realizamos a pesquisa, todas têm curso de graduação com habilitação em Pedagogia e, portanto, possuem habilitação específica, conforme determina a legislação educacional brasileira vigente.

Entretanto, percebemos que os processos de formação docente dessas professoras foram rarefeitos, em grande medida, revelando dissociação entre a teoria e a prática. Isso pode ser constatado na afirmação de uma das professoras durante a nossa pesquisa:

[...] a gente tem a teoria. No meu caso, eu tinha a teoria e quando me deparei com a prática, com a realidade da sala de aula quis entregar o cargo [de professora] na primeira semana [...]. Porque a formação [docente inicial] que a gente recebe é uma coisa, quando me deparei com a realidade é outra coisa. (BOTH, 2016, p. 270).

Em outra manifestação, a mesma professora, igualmente, evidencia a relação que teve com o conhecimento teórico no processo da formação docente inicial. Observemos:

[...] essa leitura da faculdade, do nosso curso, não é uma leitura para ler e guardar na
gaveta. É uma leitura que tem que apresentar lá na frente. O curso de professor, de
Pedagogia, é assim. Todo tempo tem que ler e apresentar lá na frente. A dificuldade
que eu passei não é só de ler aquele monte de coisa; foi de interpretar, de organizar
aula para ir à frente apresentar para os outros. Tremia mais que vara verde [...]. Não
era só eu que estava passando por aquilo, minhas colegas também. Eu pensava assim:
não sou só eu que estou com essa dificuldade. A maioria que estava ali era de escola
pública. Nós estamos trabalhando os pequenininhos agora para não ter essa
dificuldade de ir lá na frente no Ensino Fundamental, no Ensino Médio, na
Universidade. (BOTH, 2016, p. 270).

Podemos notar que o sentido da apropriação do conhecimento teórico para a professora se caracteriza mais como uma obrigação, dissociada do significado que tem para o trabalho docente. Isso, em nosso entender, tem a ver com o sentido com o qual o conhecimento teórico é abordado na formação docente.

Nas palavras de Mello (2014, p. 175): 
Quando a teoria não supera o nível do anúncio, quando não se concretiza como prática docente de nova qualidade, o que se objetiva não é uma teoria, mas um discurso sobre uma teoria. Esse risco do verbalismo é forte, especialmente na educação, dado o papel essencial da linguagem verbal na concretização do processo educativo. Sem uma teoria que oriente as intenções e as ações e, ao mesmo tempo, sem elementos mediadores que concretizem a teoria na prática sob a forma de procedimentos e relações de nova qualidade, a prática segue orientada pelo senso comum [...].

Mello ressalta a necessária unidade dialética entre a teoria e a prática, o que não significa unidade imediata entre teoria e prática na perspectiva do pragmatismo (ROSSLER, 2006). Sabemos que o pragmatismo não visa a potencializar o processo de humanização na educação escolar. A unidade entre teoria e prática, que produz humanização em quem educa e é educado, supõe que a prática seja conhecida e refletida com a mediação do conhecimento teórico, possibilitando que os fazeres sejam compreendidos e renovados à medida que o entendimento da realidade, em suas múltiplas determinações, se adensa.

Nas palavras da professora, na passagem que citamos há pouco, é possível também observar que ela faz menção aos colegas, afirmando que a maioria provém da escola pública. Isso nos remete às pesquisas realizadas por Gatti (2010) e Gatti, Barreto e André (2011), que revelam que os cursos de formação docente inicial no Brasil são procurados cada vez mais por estudantes advindos de famílias com menor poder aquisitivo que, em sua ampla maioria, frequentaram a escola da pública. Assim, em geral, tiveram poucas possibilidades de acesso ao patrimônio cultural mais elevado produzido na história da humanidade, o que concorre para uma formação mais limitada.

Do nosso ponto de vista, entretanto, não significa dizer que a esfera particular de ensino esteja imune à problemas formativos. Frequentar a escola particular, em nosso entender, não é garantia de ensino de qualidade socialmente referenciada.

Os estudantes de graduação advindos das famílias com restritas condições de vida e de educação, de acordo com as pesquisas de Gatti (2010) e Gatti, Barreto e André (2011) são principalmente os que atuam na Educação Infantil e nos anos iniciais do Ensino Fundamental em nosso país. Isso tende a gerar processos educativos mais esvaziados de conteúdo humanizador, o que contribui para obstaculizar o desenvolvimento das capacidades humanas das crianças em suas máximas possibilidades. Ninguém pode dar ao outro aquilo que lhe falta.

Como exemplo, apresentamos a fala de mais uma professora participante de nossa pesquisa. Em sua manifestação, chamamos a atenção sobre sua relação com a leitura no processo de formação anterior ao Ensino Superior. Vejamos: 
Eu tive muita dificuldade. Eu não gosto de ler. Quando entrei para a faculdade que precisou ler, eu chorava porque na família não fui acostumada a ler. Só ouvia história. [...] Eu morava num lugar onde não tinha biblioteca. A única biblioteca que tínhamos acesso era de acervo particular de um senhor que não deixava tocar nos livros dele. Mas, ele contava algumas poesias para nós. Então eu senti muita dificuldade quando fui para a faculdade. Eu chorava porque a gente tem que ler e não é pouco. É essa situação que nós não queremos que os filhos de vocês passem. (BOTH, 2016, p. 271).

Podemos perceber que a fala da professora revela a dificuldade de acesso à literatura no decurso de sua formação. Em sua opinião, isso contribui para o fato de não gostar de ler, com o que concordamos. Consideramos que essa questão levantada pela professora confirma, portanto, nossas considerações sobre a influência do acesso minguado à cultura material e simbólica na formação humana por parte da ampla maioria dos indivíduos da classe trabalhadora, o que implica em formação empobrecida.

A professora comentou, ainda, durante nossa pesquisa de campo, que teve pouca formação voltada para a Educação Infantil. Alega que aprendeu muitas coisas, atuando na prática (BOTH, 2016). Esse comentário denota traços do pragmatismo em sua formação e atuação docentes, reforçado pelo fato de que, nos cursos de formação de professores, as disciplinas e conteúdos voltados para o trabalho com a primeira infância são os mais escassos, quase sempre desenvolvidos sem que os estudantes possam estabelecer relações entre as teorias que focalizam a criança e a atividade docente que se desenrola nas creches e pré-escolas.

Assim, as manifestações das professoras participantes de nossa pesquisa, acrescidas das nossas percepções durante a investigação de campo (BOTH, 2016), nos permitem inferir que, embora todas tenham formação no Ensino Superior, não foi criada a necessidade do contínuo aprimoramento da prática pedagógica, com o auxílio dos conhecimentos teóricos. Em outros termos, podemos dizer que as professoras frequentaram a Educação Básica e o Ensino Superior, já estão atuando há mais de quinze anos nessa profissão e a apropriação teórica ainda não se tornou um carecimento em sua atuação como docentes, na perspectiva apontada por Marx (1987).

Sabemos que esse fenômeno não é fruto do acaso. São inúmeros os expedientes lançados pela classe dominante na área educacional (sucateamento das escolas; péssimas condições de trabalho; desvalorização salarial e de carreira dos professores; obsessão por metas quantitativas, por exemplo) para dificultar a socialização das formas mais ricas e desenvolvidas do conhecimento. Isso perpassa todas as etapas e níveis de ensino em nosso país.

Durante nossa investigação, observamos a presença do Instituto Áquila na escola em que realizamos a pesquisa $(\mathrm{BOTH}, 2016)$. Trata-se de uma empresa privada contratada pela 
prefeitura de Manaus para atuar junto à rede pública municipal nessa cidade. Isso, sob nosso entender, revela a ingerência de empresas privadas no setor público, uma das características do sistema capitalista (FREITAS, 2014).

Observamos que os encontros realizados pelo funcionário do Instituto Áquila na escola em que realizamos a pesquisa de campo tinham, em grande medida, um caráter informativo e descritivo. Sem uma discussão sobre os múltiplos determinantes da realidade e enfocando principalmente o controle da atividade docente, sem atenção para a formação de professores, consideramos que esses encontros guardavam semelhança com a ideia do "professor reflexivo", que pensa a prática pela prática, abordagem teórica que nutre a perspectiva da atuação docente assentada no senso comum pedagógico (BOTH, 2016).

Nesse sentido, postulamos que o Instituto Áquila tem pouca possibilidade de contribuir para o aprimoramento do trabalho educativo na perspectiva da práxis, à medida que não toma a prática como elemento a ser pensado e transformado com a mediação de teorias. Portanto, a formação continuada que estreita o elo entre a teoria e a prática na perspectiva humanizadora ainda precisa ser efetivada na unidade escolar que investigamos.

Advogamos a necessidade de que as professoras da nossa pesquisa integrem um processo de formação continuada sistemática e intencional. Essa formação compete ser pensada e realizada pela assessoria pedagógica da escola investigada, da Secretaria Municipal de Educação, contando com a colaboração das instituições de Ensino Superior que têm o compromisso de cumprir com a sua função social, dentro e fora do espaço acadêmico.

Durante nossa pesquisa de campo, foi possível perceber algumas possibilidades para a formação continuada, garantidos no Regimento Interno da unidade escolar. A pedagoga, que coordena a organização do trabalho pedagógico na escola, pode contribuir para efetivar o processo formativo, pois faz parte de suas atribuições:

IX- promover momento de estudo, reflexão da prática pedagógica a partir de formação continuada desta unidade de ensino;

$\mathrm{X}$ - disseminar práticas inovadoras, promover o aprofundamento teórico e garantir o uso adequado dos espaços de aprendizagem e dos recursos tecnológicos disponíveis nesta unidade de ensino. (BOTH, 2016, p. 274).

Sabemos que a determinação da formação continuada presente no Regimento Interno da escola não é garantia da sua efetivação. Entretanto, consideramos que a previsão regimental quanto à formação continuada é um passo importante. O passo seguinte é a luta por sua concretização.

Concordamos com Fernandes (2014), ao afirmar que: 
A valorização e o reconhecimento das escolas como espaços formativos são de fundamental importância e há anos os movimentos docentes lutam por isso, mas, no contexto atual, as escolas incorporaram as responsabilidades de formação docente sem que as condições objetivas de trabalho fossem alteradas. [...] a ausência de condições objetivas compromete significativamente a formação continuada, aprofundando as lacunas da formação inicial insuficiente e precária. (FERNANDES, 2014, p. 117-8).

Isso passa por “[...] romper o hiato entre a formação inicial e a formação continuada, pois será no exercício concreto da profissão que deverão ser buscadas as condições favoráveis ao implemento dos pressupostos formativos obtidos na formação inicial" (SILVA, 2014, p. 86). Para tanto, a atuação qualificada do coordenador pedagógico na unidade escolar é crucial. Isso pressupõe formação inicial e continuada consistente teórica e metodologicamente, a fim de estar capacitado para atuar intencionalmente para aprimorar o trabalho pedagógico dos educadores que estão sob sua responsabilidade.

Placco, Almeida e Souza (2011, p. 228, grifos das autoras) argumentam que o coordenador pedagógico tem na escola, “[...] uma função articuladora, formadora $e$ transformadora e, portanto, é o profissional mediador entre o currículo e professores e, por excelência, o formador dos professores". Na mesma obra, as autoras mencionam que as funções do coordenador pedagógico dizem respeito à “[...] articulação dos processos pedagógicos e educativos; transformação das condições pedagógicas e de ensino; e formação de professores" (PLACCO; ALMEIDA; SOUZA, 2011, p. 236).

É importante ressaltar que não temos a pretensão de atribuir toda a responsabilidade pela formação continuada das escolas aos coordenadores pedagógicos ou pedagogos. Seria, no mínimo, ingenuidade da nossa parte pensar que sozinhos seriam capazes de organizar e efetivar a formação docente continuada, pois as condições para tal empreitada estão além das suas possibilidades individuais, o que passa por reais condições de trabalho, de salário e de formação, por exemplo. Se sabemos que a realidade é construída histórica e coletivamente, em meio a lutas e contradições, colocar sobre os ombros dos indivíduos a responsabilidade por sua transformação seria negar essa historicidade.

Nosso objetivo, pelo contrário, é enfatizar o importante papel do coordenador pedagógico para enriquecer o processo educativo escolar, que deve ser objeto de trabalho de um conjunto de profissionais, em articulação com as famílias e comunidades. Para tanto, é fundamental que o pedagogo conheça efetivamente a realidade escolar e que se aproprie do Projeto Político Pedagógico da escola e de conhecimentos teóricos para atuar organizada e intencionalmente na perspectiva da práxis.

Assim sendo, o coordenador pedagógico não pode atuar de forma improvisada e 
espontaneísta, sob pena de ocupar a maior parte do tempo na escola com tarefas cotidianas demandadas por outros profissionais dentro e fora da unidade escolar. Nessa circunstância, provavelmente, tornar-se-á um tarefeiro, o que pouco contribui para o enriquecimento do processo educativo. Para nós, à medida que não se tem as rédeas do processo educativo nas mãos naquilo que for possível, a tendência é ser levado a reboque das circunstâncias que, atualmente, sabemos, estão permeadas pelas relações sociais de dominação.

Evocamos Heller (2000) para defender a criação e o desenvolvimento da capacidade homogeneizadora do coordenador pedagógico para priorizar as atividades que têm maior potencial no processo de humanização. Trata-se de ser capaz de optar por algumas atividades mirando a unidade dialética entre a prática e a teoria, o que requer colocar-se acima das demandas da cotidianidade, por inteiro. Homogeneizar-se significa, pois, concentrar todas as forças intelectuais, afetivas e morais em função da consecução de objetivos direcionados para o desenvolvimento de um trabalho que humanize a todos e a cada um. Para tanto, a apropriação de elementos culturais mais desenvolvidos, com destaque para os fundamentos teóricos que visam ao processo educativo e pedagógico, é de fundamental importância, inclusive para perceber as possibilidades existentes na escola.

$\mathrm{Na}$ escola em que realizamos a pesquisa de campo, identificamos brechas e aproveitamos para realizar atividades de formação continuada. Para exemplificar, fazemos menção ao projeto "Ler e contar histórias: contribuições para a formação de leitores envolvendo a família", que elaboramos e desenvolvemos junto com as professoras participantes de nossa pesquisa. Realizamos vários encontros envolvendo as professoras, as crianças da pré-escola e suas famílias. Isso permitiu uma maior participação de familiares na escola e a ampliação dos conhecimentos dos sujeitos envolvidos (BOTH, 2016).

As reuniões de professores e os dias destinados, no calendário letivo, à elaboração dos planos de ensino são também possibilidades que constatamos na escola lócus da nossa pesquisa. Com planejamento e organização, o coordenador pedagógico pode otimizar o tempo, reservando uma parte desses encontros para dirigir estudos fundamentados em conhecimentos sistematizados.

Sabemos que a tendência é a de que o coordenador pedagógico alegue falta de tempo pela grande demanda de trabalho dele requerida. Assim, defendemos que o coordenador pedagógico também precisa ser educado para o exercício do cargo na perspectiva humanizadora.

Entendemos que esse papel cabe especialmente às instituições de Ensino Superior. 
Entretanto, a pesquisa de Placco, Almeida e Souza (2011, p. 280) evidencia

[...] que não há formação específica para esse profissional, pois grande parte dos cursos ou espaços oferecidos a ele, em todo o Brasil, envolve questões da docência e da prática dos professores [...]. [...] cabe questionar quem é o formador do coordenador, ou quais instâncias têm-se constituído como espaço de formação. Sendo as especializações, cabe questionar sua qualidade, seus objetivos, seu público etc. Sendo instâncias do sistema, cabe questionar qual deve se responsabilizar por essa formação e de que modo deve fazê-lo, valorizando a especificidade da função.

Afirmamos ainda que, para que a escola concretize o trabalho a que se destina histórica e socialmente, a formação continuada não deve focalizar somente os coordenadores pedagógicos e professores, mas também, as merendeiras, auxiliares de serviços gerais e outros profissionais que educam ao trabalhar em unidades escolares. Ressaltamos que todos os educadores que atuam na escola necessitam estar em processo de humanização para atuarem no sentido de impelir o desenvolvimento omnilateral das crianças.

Por fim, defendemos que a formação continuada não deve se restringir à unidade escolar. Além, da importância dos cursos de pós-graduação, advogamos a necessidade de cursos que desenvolvam temas sobre questões que são comuns aos educadores que atuam na Educação Infantil da rede pública municipal de Manaus e de outros níveis de ensino. Em outros termos, asseveramos a importância da realização de atividades de formação continuada em nível de pós-graduação, mas também nas unidades escolares e em âmbito mais abrangente, que permitam refletir sobre questões concernentes à educação escolar e à classe trabalhadora, o que pode ser efetivado por intermédio da articulação entre os coordenadores pedagógicos que atuam nas escolas e outros setores do campo educacional.

Concordamos com Evangelista e Shiroma (2007) em que o desafio dos educadores é o de criar a capacidade individual e coletiva para a constituição de sujeitos históricos, capazes de se apropriarem do caráter público da escola e do conhecimento como direito social, acrescido da batalha pela socialização do patrimônio cultural produzido pela humanidade, dentro e fora das escolas. Nesse sentido, consideramos importante ressaltar que as condições para o enriquecimento da formação docente e do trabalho educativo - elementos integrantes do processo de humanização e da construção de uma sociedade para além do capital (MÉSZÁROS, 2008) - não nos serão dadas pela classe dominante. Terão que ser conquistadas por nós, da classe trabalhadora. 


\section{Considerações finais}

Se acreditamos que a realidade é construída coletivamente e que, por ser histórica, pode ser alterada pelo conjunto das pessoas, investir na formação teórico-prática de professores e professoras é um dos instrumentos fundamentais da transformação.

A consciência a respeito dos grilhões que nos submetem, como classe trabalhadora, a uma condição de desigualdade de acesso e de usufruto dos construtos da humanidade não pode ser, para nós, motivo de paralisação. Deve ser, pelo contrário, bandeira de luta constante, pois entendemos que a nossa humanidade também é construída. E isso acontece à medida que nos assenhoramos da cultura em suas expressões materiais e simbólicas. Sendo homens e mulheres, todos a ela temos direito, já que na cultura estão incrustadas as capacidades que nos humanizam, que nos afastam da animalidade, que nos permitem conhecer, conhecermo-nos e reconhecermonos responsáveis pelo nosso desenvolvimento e pela formação das novas gerações.

O conhecimento teórico, que possibilita a compreensão dessa realidade é, pois, nosso principal instrumento. É ele que nos permite ampliar e aprofundar nossa compreensão sobre o mundo, ultrapassando a cotidianidade. É o conhecimento científico que desenvolve nos professores e professoras (e, depois, nos meninos e meninas) o pensamento conceitual, capaz de criar, mentalmente, a educação a que a humanidade, como um todo, aspira. Teorizar é, portanto, também, construir objetivos que passam a mediar as ações presentes, a prática.

Os desafios que se interpõem a nossas conquistas são variados e complexos. Vivemos sob a égide de um sistema muito bem articulado. Faz-se, portanto, cada vez mais necessário que aprimoremos a nossa formação para identificar e atuar intencionalmente nas brechas oriundas das contradições que marcam a realidade. Do nosso ponto de vista, é urgente e necessário intensificar nossas ações para que a educação escolar cumpra com seu papel na socialização dos conhecimentos mais elaborados, a partir da Educação Infantil. Eis o compromisso e o desafio!

\section{Referências}

ANDRÉ, Marli E. D. A. A pesquisa no cotidiano escolar. In: FAZENDA, Ivani (org.). Metodologia da Pesquisa Educacional. 9. Ed. São Paulo: Cortez, 2004.

ANTUNES, Ricardo. Adeus ao trabalho?: ensaio sobre as metamorfoses e a centralidade do mundo do trabalho. 14. ed. São Paulo: Cortez, 2010.

ANTUNES, Ricardo. Os sentidos do Trabalho: ensaio sobre a afirmação e a negação do trabalho. 2. ed. São Paulo, SP: Boitempo, 2009. 
BOTH, Ilaine Inês. Esvaziamento do trabalho educativo na pré-escola, suas causas e implicações na formação das crianças: investigação em uma unidade escolar pública municipal em Manaus. 2016, 325f. Tese (Doutorado em Educação) - Universidade Federal do Amazonas, Manaus, 2016.

BISSOLI, Michelle de Freitas; BOTH, Ilaine Inês. Dos sentidos da formação aos sentidos do trabalho docente. In: CORREA, Carlos. Humberto. Alves; CAVALCANTE, Lucíola Inês Pessoa; AUTOR (orgs.). Formação de Professores em perspectiva. Manaus: EDUA, 2016. p. $15-55$.

BISSOLI, Michelle de Freitas. Educação e desenvolvimento da personalidade da criança. Contribuições da Teoria Histórico-Cultural. Marília, 2005, 287f. Tese (Doutorado em Educação) - Universidade Estadual Paulista "Júlio de Mesquita Filho" - Campus de Marília, 2005.

BRASIL. Lei n ${ }^{\circ}$ 9.394, de 20 de dezembro de 1996. Lei de Diretrizes e Bases da Educação Nacional. Brasília, DF, 1996. Disponível em: http://www.planalto.gov.br/ccivil_03/LEIS/L9394.htm. Acesso em: 06 abr. 2019.

CORDEIRO, J. Super-ricos estão ficando com quase toda a riqueza, às custas de bilhões de pessoas. Oxfam Brasil, 23 jan. 2018. Disponível em:

https://www.oxfam.org.br/tags/concentracao-de-riqueza. Acesso em: 04 abr. 2019.

DERISSO, José Luis. Construtivismo, pós-modernidade e decadência ideológica. In:

MARTINS, Lígia Márcia; DUARTE, Newton (orgs.). Formação de professores: limites contemporâneos e alternativas necessárias [online]. São Paulo: Cultura Acadêmica, 2010. Disponível em: <http://books.scielo.org>. Acesso em: 14 dez. 2014. p. 51-61.

ENGELS, Friedrich. Princípios Básicos do Comunismo. Obras Escolhidas de Marx e Engels em três tomos. Editorial Avante, 1982.

EVANGELISTA, Olinda; SHIROMA, Eneida Oto. Professor: protagonista e obstáculo da reforma. Educação e Pesquisa. v.33, n.3, p. 531-541, São Paulo, set./dez. 2007.

FERNANDES, Maria José Silva. Formação de professores no Brasil: algumas reflexões a partir do trabalho docente. In: MILLER, Stela; BARBOSA, Maria Valéria; MENDONÇA, Sueli Guadalupe de Lima (Orgs.). Educação e Humanização: as perspectivas da teoria histórico-cultural. Jundiaí, Paco Editorial: 2014. p.111-121.

FREITAS, Luiz Carlos. Os reformadores empresariais da educação e a disputa pelo controle do processo pedagógico na escola. Educação \& Sociedade, v. 35, p. 1085-1114, 2014.

GANDINI, Lella; GOLDHABER, Jeanne. Duas reflexões sobre a documentação. In: GANDINI, Lella; EDWARDA, Carolyn. Bambini: a abordagem italiana à educação infantil. Porto Alegre: Artmed, 2002, p. 150-169.

GATTI, Bernadete Angelina et al. A atratividade da carreira docente no Brasil. Estudos \& Pesquisas Educacionais. São Paulo: Fundação Victor Civita, 2010. 
GATTI, Bernadete Angelina. Grupo focal na pesquisa em ciências sociais e humanas. Brasília: Líber Livro Editora, 2005.

GATTI, Bernadete Angelina; BARRETO, Elma Siqueira de Sá; ANDRÉ, Marli Eliza Dalmazo de Afonso Políticas docentes no Brasil: um estado da arte. Brasília: UNESCO, 2011.

GOMES, H. S. 5 bilionários brasileiros concentram mesma riqueza que metade mais pobre no país, diz estudo. G1.globo, 22 jan. 2018. Disponível em:

https://g1.globo.com/economia/noticia/5-bilionarios-brasileiros-concentram-mesma-riquezaque-metade-mais-pobre-no-pais-diz-estudo.ghtml. Acesso em: 04 abr. 2019.

HELLER, Agnes. O cotidiano e a história. Tradução de Carlos Nelson Coutinho e Leandro Konder. 6. ed. São Paulo: Paz e Terra, 2000.

LEHER, Roberto. Educação no capitalismo dependente ou exclusão social? In: MENDONÇA, Sueli Guadelupe de Lima; SILVA, Vandeí Pinto da S.; MILLER, Stela. (orgs.). Marx, Gramsci e Vigotski: aproximações. 2. ed. Araraquara, SP: Junqueira \& Marin, 2012. p. 223-251.

MACIEL, Camila. Patrimônio dos 26 mais ricos do mundo equivale ao da metade mais pobre. Agência Brasil, 21 jan. 2019. Disponível em:

http://agenciabrasil.ebc.com.br/economia/noticia/2019-01/patrimonio-dos-26-mais-ricos-domundo-e-igual-ao-da-metade-mais-pobre. Acesso em: 04 abr. 2019.

MARX, Karl. Manuscritos Econômico-Filosóficos e outros textos escolhidos. Coleção Os Pensadores, 4. ed. São Paulo: Nova Cultural, 1987.

MELLO, Suely Amaral. O desenvolvimento da linguagem oral, escrita e visual. In: BISSOLI, Michelle de Freitas (org.). Fundamentos da Educação Infantil. Manaus: CEFORT/EDUA, 2007.

MELLO, Suely Amaral. Teoria Histórico-Cultural e trabalho docente: apropriação teórica e novas relações na escola. In: MILLER, Stela.; BARBOSA, Maria Valéria; MENDONÇA, Sueli Guadalupe de Lima (orgs.). Educação e Humanização: as perspectivas da teoria histórico-cultural. Jundiaí, Paco Editorial: 2014. p. 173-180.

MÉSZÁROS, István. A educação para além do capital. Tradução Isa Travares. 2 ed. São Paulo: Boitempo, 2008.

MILLER, Stela; BARBOSA, Maria Valéria; MENDONÇA, Sueli Guadalupe de Lima (orgs.). Educação e Humanização: as perspectivas da teoria histórico-cultural. Jundiaí, Paco Editorial: 2014.

MINAYO, Maria Cecília de Souza. O desafio do conhecimento: pesquisa qualitativa em saúde. 12 ed. São Paulo: Hucitec, 2010. 
MORAES, Maria Célia Marcondes de. Recuo da teoria: dilemas na pesquisa em educação. In: Revista Portuguesa de Educação, Braga, Portugal, Universidade do Minho, v. 14, n. 1, p. 7-25, jan./jun. 2001.

MORAES, Maria Célia Marcondes de. "A teoria tem consequências": indagações sobre o conhecimento no campo da educação. Educação \& Sociedade. Campinas, v. 30 n.107, p. 585- 607, maio/ago, 2009. Disponível em: http://www.cedes.unicamp.br. Acesso em: 10 ago. 2015.

PLACCO, Vera Maria Nigro de Souza; ALMEIDA, Laurinda Ramalho; SOUZA, Vera Lucia Trevisan de. O coordenador pedagógico (CP) e a formação de professores: intenções, tensões e contradições. Estudos \& Pesquisas Educacionais, Fundação Victor Civita, 2011. Disponível em: http://www.fvc.org.br/pdf/livro2-04-coordenador.pdf. Acesso em: 20 nov. 2015.

ROSSLER, João Henrique. Sedução e alienação no discurso construtivista. Campinas, SP: Autores Associados, 2006.

SHIROMA, Eneida Oto. O eufemismo da profissionalização. In: MORAES, Maria Celia Marcondes de (org.). Iluminismo às avessas: produção de conhecimento e políticas de formação docente. Rio de Janeiro: DP\&A, 2003. p. 61-79.

SILVA, Vandeí Pinto. Formação de professores na perspectiva da filosofia da práxis: quem educa o educador? In: MILLER, Stela; BARBOSA, Maria Valéria; MENDONÇA, Sueli Guadelupe. de Lima (orgs.). Educação e Humanização: as perspectivas da teoria históricocultural. Jundiaí: Paco Editorial, 2014. p. 83-96. 